Pre-print version of the accepted manuscript. Please cite as: Biesbroek, G.R., Dupuis, J. and A. Wellstead (2017) Explaining through Causal Mechanisms: Resilience and Governance of Social-Ecological Systems. Current opinion in Environmental Sustainability 28:64-70.

\title{
Explaining through Causal Mechanisms: Resilience and Governance of Social-Ecological Systems
}

Dr Robbert Biesbroek*, Assistant Professor, Public Administration and Policy group, Wageningen University \& Research, the Netherlands

Dr Johann Dupuis, Senior Researcher, IDHEAP, Swiss Graduate School of Public Administration, University of Lausanne, Switzerland

Dr Adam Wellstead, Associate Professor of Environmental and Energy Policy, Michigan Technological University, USA

*corresponding author: robbert.biesbroek@wur.nl, Hollandseweg 1,6700AA, Wageningen, the Netherlands

\begin{abstract}
This paper synthesizes and builds on recent critiques of the resilience literature; namely that the field has largely been unsuccessful in capturing the complexity of governance processes, in particular cause-effects relationships. We demonstrate that absence of a causal model is reflected in the black-boxing of governance processes which is problematic for resilience studies with explanatory ambitions. We introduce mechanism-based thinking as alternative research perspective that offers more analytical rigour and elaborate the key principles of this approach. Mechanism-based approaches are aligned to the ways of thinking in systems theory and complexity sciences and can be used to advance scientific inquiry and policy practice to govern complex sustainability issues.
\end{abstract}

\section{Introduction}

Originally coined by ecology scholars [1], the goal of building resilience in social-ecological systems has gained considerable traction over the past decade, particularly from environmental scientists and interdisciplinary scholars. Moreover, resilience thinking has entered the public and political arenas as a popular mantra for dealing with many of the contemporary complex or 'wicked' problems such as food (in)security, climate change impacts, incurable pollution, natural resource (mis)management, or species exploitation. Resilience is often seen as boundary object as it remains sufficiently vague, ambiguous and malleable to unite different scientific disciplines in inter and transdisciplinary research on complex societal issues [2]. However, critiques have emerged from other fields of study such as sociology and political science about what resilience actually means and its utility as an explanatory concept, specifically when it comes to understanding the governance of these complex sustainability issues [3,4].

The complexity and nonlinearity of socio-ecological systems has led resilience scholars to question traditional modes of governance as they are deemed ill-equipped to result in better and more resilient outcomes. Consequently, a plethora of conceptualisations and frameworks to analyse the governance of social-ecological systems have emerged in this literature, including adaptive governance [5], co-productive governance [6] and, more recently, transformative environmental governance [7]. These frameworks and approaches each emphasize specific principles that are considered necessary to improve the state of socioecological systems and make them more resilient and withstand disruptions, including 
Pre-print version of the accepted manuscript. Please cite as: Biesbroek, G.R., Dupuis, J. and A. Wellstead (2017) Explaining through Causal Mechanisms: Resilience and Governance of Social-Ecological Systems. Current opinion in Environmental Sustainability 28:64-70.

principles of adaptive management such as active monitoring and policy experimentations, polycentric institutions, participation and co-production of collective decisions, individual and social learning, flexibility and robustness, and use of local knowledge $[1,4,5,8]$. Although advocating for a comprehensive, science based approach to explain the governance of resilience, emphasis in most of this literature is placed on the normative question of how things ought to be, rather than explaining how things are and why things are the way they are.

This paper aims to advance scientific scholarship on the governance of resilience by proposing a mechanism-based approach. We argue that a different research perspective is needed, in line with Karl Popper's argument that the essence of (social) sciences is about "putting forward and testing theories" [9]. Resilience literature in general and specifically when it comes to the role of governance is under-theorized and suffers from the "problem of induction". This means that crude generalizations to universal statements of particular observations are made based on a limited number of cases. To take social science research seriously, studies with explanatory ambitions must have an underlying causal model that allows to theorize cause-effect relationships and distil or test the operative causal mechanisms. This has been too rarely the case in the existing resilience literature.

After synthesising the major critiques of the resilience literature's conceptualization of governance, we introduce mechanism-based approaches in order to look into the black-box of governance processes and discuss causal mechanisms as a way to capture the processes through which certain effects are produced. We conclude by reflecting on the value of mechanism-based thinking for furthering the scientific inquiry in the resilience literature and support policy practice in making more informed decisions about governing socio-ecological systems.

\section{Key critiques on the resilience literature}

Throughout the governance-orientated resilience literature, the concept of resilience has been employed in two ways [4]. First, it is used to describe the state of an existing social-ecological system responding to system perturbations. For example, McGreavy et al [10] apply resilience concepts in order to examine the role of citizen science and program design of vernal pool policy innovation in Maine. Second, much of the literature starts from the normative principles that resiliency of a system is improved by implementing principles of adaptive governance. For instance, Gunderson and Light [11] analyse the exemplary case of the Everglades, a unique wetland ecosystem in Florida which, according to the authors, was deteriorated by years of top-down control of public agencies over water supply and flood risks. While they recognize to some extent the merits of restoration policy, the authors criticize its overly planned and scientific management, and advocate for transitions to adaptive governance, which would imply amongst others, an experimental approach to continuously increase the response capacity to the next crises, as well as fostering cooperation by improving the links between individuals, stakeholders, social organizations, and public agencies at all levels [11].

These normative aspects underlying resilience literature are problematic as they usually remain implicitly implied nor justified ethically or politically [2]. For example, democratic theory questions the underlying principles of adaptive governance to challenge existing institutions and public procedures. It might not always be beneficial to the ecosystem to adopt adaptive governance, and may very well increase the risks of unaccountability of decisionmakers, inefficiencies, unequal access to the decision arenas, and political power play as 
Pre-print version of the accepted manuscript. Please cite as: Biesbroek, G.R., Dupuis, J. and A. Wellstead (2017) Explaining through Causal Mechanisms: Resilience and Governance of Social-Ecological Systems. Current opinion in Environmental Sustainability 28:64-70.

result of vested interests, certainly in cases where economic interests in ecosystem exploitation dominate local politics [12]. Arguably, resilience is an ecological concept that has been stretched to such extent that it clearly no longer captures the original meaning when applied in a social science context [3]. Resilient societies are those that are able to undergo external shocks and maintain the same identity, structure and ways of functioning. As several scholars have argued, the concept of resilience by ignoring ethics and power relations cannot be meaningfully applied as a framework to assess societies and governance systems, but only to ecosystems [13].

Most of the literature asserts that to increase the resiliency of an ecological system, the governance system needs to approximate the ideal of adaptive governance, or at least conform to some of its principles. However, it hardly theorizes about the underlying cause-effects when it comes to governance processes. Both the theoretical foundations as well as empirical evidence supporting this presumed causal relationship remain unclear. Consequently, the pathways through which existing governance structures and processes could be made adaptive is hardly explained. To illustrate, we reviewed over 100 recent scientific papers with explanatory ambitions that addressed explicitly the governance of socio-ecological systems and resilience ${ }^{1}$, focussing particularly on how adaptive governance contributes to resilient ecosystems. We found surprisingly few papers with a clear causal model. Most of the recent work is referencing to Olsson et al. [14-15] who analyze ten case studies of transitions towards adaptive governance in the USA, in Sweden, Thaïland, Australia and Canada. Borrowing heavily from political scientist Kingdon, Olsson and colleagues conclude that successful transformations toward adaptive governance is the result of a social mechanism that is contrived of (a) key leadership by a policy entrepreneur, (b) seizing of a window of opportunity opened due to an external shock, and (c) building resilience based on adaptive governance principles. This explanation is, however, deceiving for social scientists and policy scholars as Kingdon's framework is known to be a descriptive heuristic, and not a theoretical model developed to formulate hypothesis on the causes and effects of governance changes [16].

The resilience literature is therefore characterised by a mismatch between recognizing the social-political dynamics and the ways through which these are studied. Much of the resilience literature emphasizes that processes of governance have to navigate deep system uncertainties, a plurality of interdependent actors that crosscut traditional boundaries of sectors, levels and types, and take part in a highly erratic, chaotic, and politicized decision making processes over socio-ecological systems [14,17], a governance paradigm shared with contemporary public policy theories [18]. However, when studying these processes, the existing theories, concepts and frameworks are ill-equipped to address explanatory questions.

The underlying cause for this mismatch is that most - but certainly not all [19] - of the literature with explanatory ambitions is rooted in a functionalist logic. Socio-economic and bio-physical systems are considered as so closely interlinked that the complexities of, for example, political order and policy process dynamics are reduced to functions of the larger social-ecological systems. According to this line of thought, well functioning socialecological systems are expected to generate appropriate responses by developing new or different types of policy to ensure resilience is improved [20]. The highly dynamic processes

\footnotetext{
${ }^{1}$ From the Scopus database, the following text search was conducted: [(Resilience) AND (Adaptive Governance) AND (Mechanism)]. The initial search yielded 102 articles of which 42 were relevant and explored in detail.
} 
Pre-print version of the accepted manuscript. Please cite as: Biesbroek, G.R., Dupuis, J. and A. Wellstead (2017) Explaining through Causal Mechanisms: Resilience and Governance of Social-Ecological Systems. Current opinion in Environmental Sustainability 28:64-70.

of politics and power are reified into simplified and static classifications of (possible) variables with clear functions in the system. Implicitly, the argument is that improving certain functions in the social-ecological system (i.e. introducing better models of governance, polycentric structures, or adaptive policies) will automatically result in more resilient systems. Consequently, failure to do so, for example because of the presence of certain barriers, will decrease the chances of successful transitions towards more resilient systems [21-23]. This simplistic intervention logic is highly problematic as it is not based on detailed and in-depth understanding of causation, as authors tend to claim, but rather based on normative principles and unproven heuristics that dominate the resilience literature [24].

\section{Thinking inside the box $^{2}$ : causal mechanisms}

This dominant perspective in the resilience literature follows closed-systems thinking, resulting in a functional input-out model of decision making in which the actual cause-effect relations of analytical interest are black-boxed. Some studies are 'grey-boxed' meaning that they provide insights in the governance process, but without making causal linkages explicit [25]. Not considering causality cancels the possibility for explanatory research and limits the predictive power of the resilience literature. Given these critiques, we argue that in order to advance scientific debates and propose meaningful and scientifically informed governance interventions, we need to take causality seriously when explaining the governance of socioecological systems and resilience.

Several leading mechanisms scholars, including Beach and Pedersen [26] and Goertz and Mahoney [27] argue that two main ontological positions exist in the social sciences when it comes to causality: the first position understands causation as regular association, which means that causation is understood ".... as regular patterns of $\mathrm{X} \rightarrow \mathrm{Y}$ associations, and the causal processes whereby X produces $\mathrm{Y}$ is black boxed” [26, p25). Resilience researchers usually respond to this black box problem - if at all - by speculating about the reasons why the observed association exists, building on earlier studies, or general concepts that prevail in the resilience literature [27].

The second position which is central to the rest of this paper is rooted in works of amongst others Bunge [28], Pawson and Tilley [29], Hedstrom and Ylikoski [30], Mahoney [31], and Gerring [32]. Their understanding of causality is rooted in generative mechanisms whereby "...X produces $\mathrm{Y}$ and in particular in the transmission of what can be termed causal forces from $\mathrm{X}$ to $\mathrm{Y}$ ” [26, p25]. Causality is not a functional description of a certain variable, but rather the dynamic and interactive influence of (several) processes that produce an effect at a certain moment in time and under certain conditions [33].

Central to this position are the efforts of uncovering the causal mechanism(s) as these explain how $\mathrm{X}$ actually produces $\mathrm{Y}$. There are many definitions of what might constitute a mechanism (see Mahoney [31] and Hedstrom and Ylikoski [30]), but mechanisms are generally referred to as an unobservable but empirically traceable process that acts as a cause in generating the outcome and which, in principle, does not need further elaboration as the mechanism is selfevident and self-explanatory. Some authors have argued that there is always one causal mechanism in play, whereas others consider that there can be a chain of different mechanisms that configuratively explain how certain effects or outcomes are produced [26]. In order to understand the various interpretations, Falleti and Lynch [34] propose that mechanism-based explanations can be classified into mechanisms-as-types, mechanisms-as-examples,

\footnotetext{
${ }^{2}$ Based on Gerring's [32] title: The mechanismic worldview - thinking inside the box.
} 
Pre-print version of the accepted manuscript. Please cite as: Biesbroek, G.R., Dupuis, J. and A. Wellstead (2017) Explaining through Causal Mechanisms: Resilience and Governance of Social-Ecological Systems. Current opinion in Environmental Sustainability 28:64-70.

mechanisms-as-indicators and mechanisms-as-cause. Any mechanism-based explanation then needs to identify and measure at least one 'mechanism-as-cause' for it to be considered a mechanism-based explanation.

Identifying configurations of causal mechanisms allows for specific problem-solving. For instance, unravelling the set of chemical and biological mechanisms that causally connects lung cancer to smoking cigarettes is a vital and necessary step towards increasing public health [35]. Mechanism based-approach is not only central in health sciences, but is closely linked to systems theory, complexity sciences, and natural science principles upon which the social-ecological systems theory builds.

The value of the mechanism-based approach is that theorized mechanisms can operate transfactually thereby creating the possibility for abstract and normic generalizations about the cause-effect relationship [34]. This means that mechanisms are portable concepts for which the theorized structure of the mechanism is free of context. Examples of causal mechanisms frequently emerging in the social science literature include self-fulfilling prophecies, spill-over effects, and dialogues of the deaf, see Table 1. Unlike the natural sciences, where a certain mechanism is always responsible for the same outcome, there are no social science laws and consequently mechanisms that are unconditionally true. Merton [36] therefore argues that mechanisms form the building blocks of middle range social theories, or 'sometimes true' theories.

Table 1: Example of governance mechanisms found in social science literature

\begin{tabular}{|c|c|c|c|}
\hline $\begin{array}{l}\text { Types of } \\
\text { Mechanisms }\end{array}$ & $\begin{array}{l}\text { Examples of } \\
\text { mechanisms }\end{array}$ & Description & Key Authors \\
\hline \multirow[t]{4}{*}{$\begin{array}{l}\text { Cognitive- } \\
\text { behavioural }\end{array}$} & Belief formation & $\begin{array}{l}\text { People act in accordance with signals from others } \\
\text { about the likely value or necessity of an act. }\end{array}$ & $\begin{array}{l}\text { Hedström and } \\
\text { Swedberg } \\
\text { [37] }\end{array}$ \\
\hline & Brokerage & $\begin{array}{l}\text { Mediating unit (group or individual) links two or more } \\
\text { previously unconnected social arenas. }\end{array}$ & $\begin{array}{l}\text { McAdam, Tarrow and } \\
\text { Tilly [38] }\end{array}$ \\
\hline & $\begin{array}{l}\text { Self-fulfilling } \\
\text { prophecies }\end{array}$ & $\begin{array}{l}\text { False definition of the situation evoking a new } \\
\text { behavior which makes the original false conception } \\
\text { come true }\end{array}$ & Merton [39] \\
\hline & $\begin{array}{l}\text { Logic of } \\
\text { appropriateness }\end{array}$ & $\begin{array}{l}\text { Actors do what they see as appropriate and right for } \\
\text { themselves in a specific type of situation rather than } \\
\text { what cost-benefit calculations consider optimal (i.e. } \\
\text { logic of consequences) }\end{array}$ & March and Olsen [40] \\
\hline \multirow[t]{3}{*}{$\begin{array}{l}\text { Interactional } \\
\text { and relational }\end{array}$} & Blame avoidance & $\begin{array}{l}\text { (Political) actors are motivated primarily by the desire } \\
\text { to avoid blame for unpopular actions rather than by } \\
\text { seeking to claim credit for popular ones }\end{array}$ & Hood [41] \\
\hline & $\begin{array}{l}\text { Frame } \\
\text { polarization }\end{array}$ & $\begin{array}{l}\text { Process between actors in which the framing distance } \\
\text { between opposing groups increases due to repeated } \\
\text { reaffirmation of the same point }\end{array}$ & $\begin{array}{l}\text { Dewulf and Bouwen } \\
\text { [42] }\end{array}$ \\
\hline & $\begin{array}{l}\text { Dialogues of the } \\
\text { deaf }\end{array}$ & $\begin{array}{l}\text { Interaction in which each party is unresponsive to what } \\
\text { the others say resulting in that people talk past each } \\
\text { other }\end{array}$ & van Eeten [43] \\
\hline \multirow[t]{4}{*}{$\begin{array}{l}\text { Institutional/ } \\
\text { Structural }\end{array}$} & Increasing returns & $\begin{array}{l}\text { Systems persist or grow via decreasing costs because } \\
\text { of positive network externalities }\end{array}$ & Theelen [44] \\
\hline & Layering & $\begin{array}{l}\text { Progressive amendments and additions slowly change } \\
\text { the existing institutions and systems }\end{array}$ & $\begin{array}{l}\text { Mahoney and Thelen } \\
\text { [45] }\end{array}$ \\
\hline & Conversion & $\begin{array}{l}\text { Introduction of new goals, functions, and purposes } \\
\text { redirect existing institutions and systems toward an } \\
\text { alternative state. }\end{array}$ & $\begin{array}{l}\text { Mahoney and Thelen } \\
\text { [45] }\end{array}$ \\
\hline & Policy drift & $\begin{array}{l}\text { Outputs and outcomes of policies change when the } \\
\text { policies are not adapted to new circumstances }\end{array}$ & Hacker [46] \\
\hline
\end{tabular}


Pre-print version of the accepted manuscript. Please cite as: Biesbroek, G.R., Dupuis, J. and A. Wellstead (2017) Explaining through Causal Mechanisms: Resilience and Governance of Social-Ecological Systems. Current opinion in Environmental Sustainability 28:64-70.

There are a variety of frameworks that have been developed in the literature to study causal mechanisms. For example, the seminal works of McAdam, Tarrow, and Tilly [38] identifies structural and macro-level causal mechanisms that recur across a wide range of contentious politics, including mechanisms of brokerage, category formation, and elite defection. Some scholars have argued that mechanisms should be considered at the micro-level, where individual behaviour and agency is most clearly observed. Others consider that the configuration of mechanisms that link micro-macro levels are of critical importance. These distinctions are nicely captured in the 'bath-tub model' developed by Hedstrom and Swedberg [37], who highlight different levels of mechanisms: Situational (macro to micro mechanisms), Action-formation (micro to micro mechanisms); Transformative (micro to macro mechanisms), which allows to connect the different types of mechanisms identified in Table 1, see Figure 1.

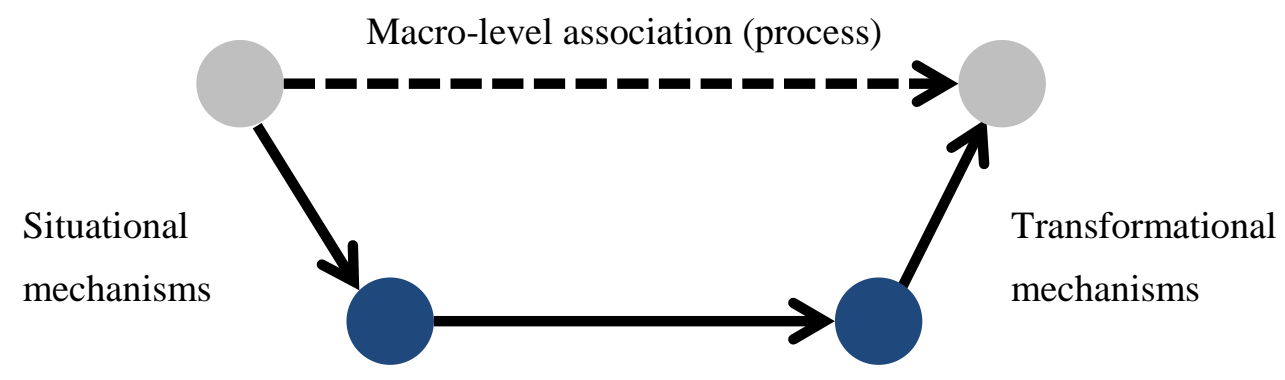

Action formation mechanisms

Figure 1: Bath tub model for identifying different type of mechanisms and their interplay [37].

Providing a causal explanation requires careful consideration of the interaction between the mechanism(s) and the contextual conditions within which the mechanism operates [47]. It is argued that the set of initial conditions play a pivotal role in determining if, when, and how certain mechanisms are triggered and how they might only play out under certain contextual conditions. Context is important as it allows for more formulating more refined hypothesis by specifying under which conditions certain mechanisms are most likely to occur or produce a certain effect $[29,48]$. Recent studies therefore stipulate that mechanism-based explanations have to take contextual conditions seriously in their explanations. Several scholars have used the so-called $\mathrm{C} \rightarrow \mathrm{M} \rightarrow \mathrm{O}$ model to include context in their mechanism-based models: the Observed patterns of (un)intended outcomes can be explained by identifying the plausible causal set of Mechanisms within the situational Context of the process (Figure 2). The need for considering context responds to empirical observations that similar initial conditions may lead to dissimilar outcomes (multifinality) and that a certain outcome can be reached from any number of different developmental paths (equifinality) [47]. 
Pre-print version of the accepted manuscript. Please cite as: Biesbroek, G.R., Dupuis, J. and A. Wellstead (2017) Explaining through Causal Mechanisms: Resilience and Governance of Social-Ecological Systems. Current opinion in Environmental Sustainability 28:64-70.

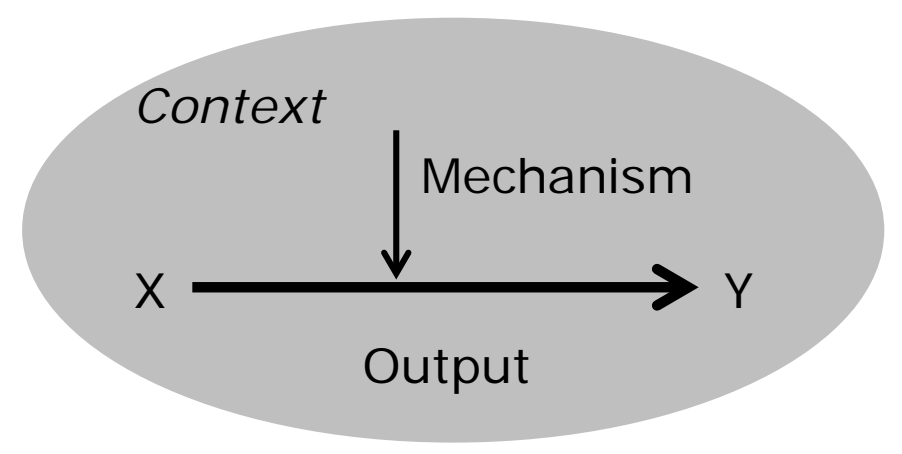

Figure 2: CMO model of understanding how context influences mechanisms and output [29].

\section{Uncovering causal mechanisms: methodological considerations}

The question is, of course, how to distil mechanisms and determine causality. Several ways have been proposed to determine deterministic or probabilistic causes by either uncovering generative mechanisms or testing hypothesized mechanisms at work, including methods of mechanism experiments [49], Bayesian logics [50], process tracing [26] or combinations such as Qualitative Comparative Analysis with process tracing methods [51]. Process tracing is one popular method for unearthing mechanisms and determining causality. Process tracing is often compared to 'detective work' and 'court trials' where the analyst has to trace and reconstruct the exact course of events and be able to provide compelling evidence to convince a judge/jury [52]. Process tracing is no easy task and is highly demanding for the researcher, both in terms of resources and intellectual capacity. Kay and Baker [53] offer a comprehensive review of the potential pitfalls (and ways to remedy them) for causal process tracing.

Figure 3 illustrates how a process tracing methodology could be used to 'open-up the black box' of governance processes for socio-ecological systems [26]. It shows that multiple episodes of activities exist between different types of actors within a given context.

Depending on whether causal process tracing method is theory driven or generative, the first step is to either develop specific theoretical expectations or reconstruct the sequence of empirical events. In both cases, the analysts' task is to use the empirical observations to uncover the causal mechanism by cycling back and forth between the observable empirical world and unobservable theoretical levels [22]. Different sources of data can be used which offer different degrees of confidence in the strength of the mechanism-based explanation; Beach and Pedersen identify four types of evidence that are relevant in process-tracing: pattern, sequence, trace, account [26]. Although there are many processes that could be called mechanisms, process tracing aims to distil the (set of) mechanisms-as-cause that exclude alternative explanations with a high confidence. As discussed above, mechanisms can be found at different analytical levels, and no clear stopping rules exist for identifying the underlying mechanism of a mechanism (i.e. micro-level mechanisms of 'escalation' might explain the macro-level mechanism of the 'hurting stalemate'). Although there always could be a lower lying mechanism, the rule of the thumb is to stop searching when the underlying mechanisms do not provide better insights in the cause-effect chain. 
Pre-print version of the accepted manuscript. Please cite as: Biesbroek, G.R., Dupuis, J. and A. Wellstead (2017) Explaining through Causal Mechanisms: Resilience and Governance of Social-Ecological Systems. Current opinion in Environmental Sustainability 28:64-70.

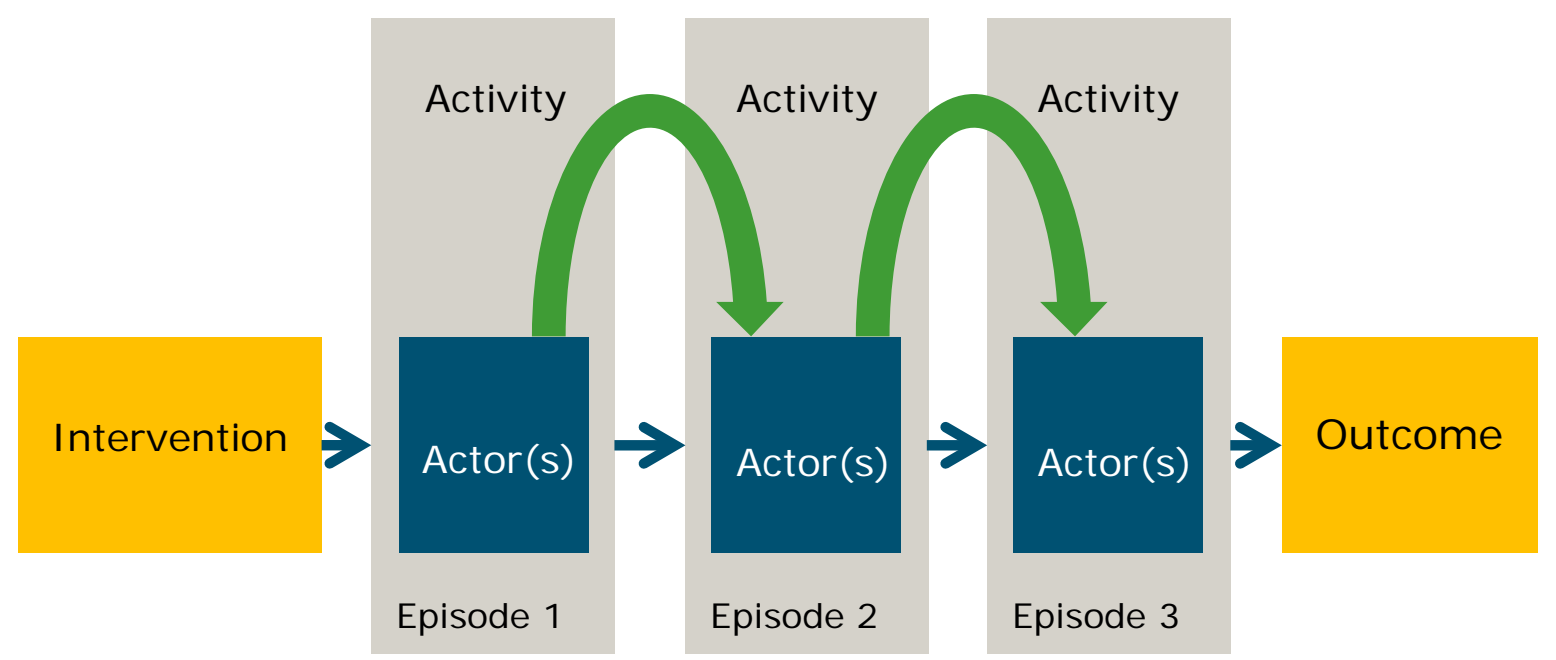

Figure 3. Chain of different episodes (with specific contextual conditions) and configuration of mechanisms (arrows) that can causally explain the observed outcome [26].

There are different ways to establish which mechanisms are mechanisms-as-cause. One possibility is to develop a counterfactual framework using quasi experimental set-ups, agency based models, or by engaging in thought experiments to critically reflect on whether or not the observed outcome would still have been reached without the mechanism. Recently various studies within the political sciences have successfully adopted this in their the process tracing approach to study complex social-political systems and explain through generative mechanisms. A recent example is provided by Hinterleitner [54] who investigates a contentious case on how a political blame game around an expensive therapy setting for a youth offender in Switzerland produced elite polarisation. Another example is the research by Adams [55], who hypothesizes how the mechanism of decentralization influences various outcomes, including interjurisdictional competition and the accommodation of heterogeneous preferences.

\section{Concluding reflections and next steps}

We have argued in this paper that the concept of resilience has been stretched to such extent that explanatory research is proving difficult, specifically when it comes to questions related to how governance processes produce certain outcomes. The underlying functionalist logic of the resilience literature makes that it does not live up to the explanatory value often ascribed to it. Without a meaningful approach to causation it becomes problematic, if not impossible, to explain the complexity of processes that shape resilience, or how resilience shapes the functioning of social-ecological systems. The mechanism-based approach presented in this paper offers more analytical rigour by answering question of "how" and "why" certain outcomes are produced. This approach is epistemologically aligned to the ways of thinking in the systems theory, complexity sciences, and implicitly in most natural sciences. Although the mechanism-based approach has been advocated by many and discussed in different social sciences, it has hardly entered the study of socio-ecological systems.

We argue that the mechanism-based approach offers a fruitful way to advance both scientific debates and policy practice of the governance of socio-ecological systems. For scientific progress as it offers a rigorous type of scientific inquiry to study crucial governance processes, to test some hypotheses, and debunk some prevailing and untested heuristics in the literature. For policy practice the mechanism-based approach can be valuable as it makes 
Pre-print version of the accepted manuscript. Please cite as: Biesbroek, G.R., Dupuis, J. and A. Wellstead (2017) Explaining through Causal Mechanisms: Resilience and Governance of Social-Ecological Systems. Current opinion in Environmental Sustainability 28:64-70.

intelligible which causal mechanisms are in play and becomes an important anchorage point for policy practitioners to strategically intervene in governance processes and help guide decision making towards how things ought to be.

\section{References}

* are of interest to the reader

** are of high interest to the reader

[1] Béné C, Mehta L, McGranahan G, Cannon T, Gupte J, Tanner T.: Resilience as a policy narrative: potentials and limits in the context of urban planning. Clim Dev 2016 29:1-18.

[2] Brand, FS., and K Jax: Focusing the meaning(s) of resilience: resilience as a descriptive concept and a boundary object. Ecol. and Soc. 2007 12(1): 23

[3] *Davidson DJ: The Applicability of the Concept of Resilience to Social Systems: Some Sources of Optimism and Nagging Doubts. Soc.\& Nat. Res., 2010 23(12): 1135-1149.

- Although frequently used by ecologists and environmental scholars, the author of this paper argues that resilience is not readily applicable to social systems and requires further theoretical development in system complexity and agency. This paper provides a comprehensive overview and social science critique and formulates possible ways forward.

[4] **Olsson L, Jerneck A, Thoren H, Persson J, O’Byrne D: Why resilience is unappealing to social science: Theoretical and empirical investigations of the scientific use of resilience. Science Adv. 2015: 1(4).

- This paper offers a detailed account of the main problems the concept of resilience entails. It unpacks the main critiques found in various strands of the social science literature in a very accessible and informative way.

[5] *Karpouzoglou TD, Dewulf ARPJ, Clark J: Advancing adaptive governance of socialecological systems through theoretical multiplicity Env. Sci. \& Pol. 2016 57:1-9.

- This systematic review paper offers recent insights in how the concept of adaptive governance is being used and which theoretical principles it rests. The authors argue that using multiple theoretical lenses is necessary to better understand the ways in which complex issues can be governed.

[6] Wyborn C: Co-productive governance: a relational framework for adaptive governance. Glob. Env. Chan. 2015 30:56-67

[7] *Chaffin BC, Garmestani AS, Gunderson LH, Benson MH, Angeler DG, Arnold CA, .. . Allen, CR: Transformative environmental governance. Ann. Rev. of Env. and Res. 2016 41: 399-423.

- Building on the strengths and weaknesses of adaptive governance scholarship, the authors argue that transformative environmental governance is an important paradigm that better captures the capacity needed to fundamentally change or create new socioecological regimes. It offers an additional set of governance principles that are considered necessary to respond to regime shifts 
Pre-print version of the accepted manuscript. Please cite as: Biesbroek, G.R., Dupuis, J. and A. Wellstead (2017) Explaining through Causal Mechanisms: Resilience and Governance of Social-Ecological Systems. Current opinion in Environmental Sustainability 28:64-70.

[8] Huitema D, Mostert E, Egas W, Moellenkamp S, Pahl-Wostl, C, Yalcin. R: Adaptive water governance: assessing the institutional prescriptions of adaptive (co-)management from a governance perspective and defining a research agenda. Ecol. and Soc.2009 14(1): 26

[9] Popper K: The logic of scientific discovery, Routledge; 2002.

[10] McGreavy B, Calhoun A, Jansujwicz J, Levesque V: Citizen science and natural resource governance: program design for vernal pool policy innovation. Ecol. and Soc. $201621(2)$.

[11] Gunderson L, and Light SS: Adaptive management and adaptive governance in the everglades ecosystem. Policy Sci, 2006 39(4), 323-334.

[12] Papadopoulos Y, and Warin P: Are innovative, participatory and deliberative procedures in policy making democratic and effective? Europ. Jour. of Pol. Res. 2007 46(4): 445-472.

[13] Anderies JM, Folke C, Walker B, and Ostrom E: Aligning Key Concepts for Global Change Policy: Robustness, Resilience, and Sustainability. Ecol. and Soc. 2013 18(2).

[14] Olsson P, Gunderson LH, Carpenter SR, Ryan P, Lebel L, Folke C, Holling CS: Shooting the Rapids: Navigating Transitions to Adaptive Governance of SocialEcological Systems. Ecol. and Soc. 2006 11(1).

[15] Olsson P, Folke C, Berkes F: Adaptive Co-management for Building Resilience in Social-Ecological Systems. Env. Managem. 2004 34(1), 75-90.

[16] Cairney P, Jones MD: Kingdon's Multiple Streams Approach: What Is the Empirical Impact of this Universal Theory? Pol. Stud. Jour. 2016 44(1), 37-58.

[17] *Duit A, Galaz, V: Governance and Complexity-Emerging Issues for Governance Theory. Governance, 2008 21: 311-335

- Existing governance theories are exploring the ways in which nonlinear dynamics, threshold effects and cascades should be considered. Building on complex adaptive systems thinking the authors offer a range of insights on how to advance the current governance paradigm to better govern socio-ecological systems.

[18] *Torfing J, Peters BG, Pierre J, Sorensen E: Interactive Governance: Advancing the Paradigm. Oxford University Press: 2012.

- This already seminal book offers a comprehensive overview and synthesis of recent insights governance theory. Leading scholars in this field argue that much of the recent developments can be captured under the paradigm of interactive governance whereby state-society-market are interdependent and continuously interact. The book offers a range of recent insights on dimensions of governance, power, democracy, and measurement of governance . 
Pre-print version of the accepted manuscript. Please cite as: Biesbroek, G.R., Dupuis, J. and A. Wellstead (2017) Explaining through Causal Mechanisms: Resilience and Governance of Social-Ecological Systems. Current opinion in Environmental Sustainability 28:64-70.

[19] Ingalls ML, Stedman RC: The power problematic: Exploring the uncertain terrains of political ecology and the resilience framework. Ecol. and Soc.2016, 21(1).

[20] * Wellstead A, Howlett M, Rayner J: Structural-functionalism redux: adaptation to climate change and the challenge of a science-driven policy agenda. Crit. Pol. Stud. 2016 $1-20$.

- The authors argue that much of the climate change adaptation literature is characterized as being 'functionalist' in nature and that this is reflected in the ways in which policy processes are understood and conceptualized. Illustrated by case studies from across the (developed) world the authors show how functionalism impacts how science-policy interactions are impacted.

[21] *Biesbroek GR, Dupuis J, Jordan A, Wellstead A, Howlett M, Cairney P, Rayner J, Davidson D: Opening the black box of adaptation decision making Nat. Clim. Chan. 2015 5(6): 493-494

- Several avenues for moving the 'barriers to adaptation' discussion forward have been proposed. These public policy scholars argue that fundamental ontological reconsideration is needed in order to advance scientific inquiry about the reasons why governing the process of adaptation to climate change impacts proves so challenging.

[22] **Biesbroek GR, Termeer CJAM, Klostermann JEM, Kabat P: Rethinking barriers to adaptation: mechanism-based explanation of impasses in the governance of an innovative adaptation measure. Glob. Env. Chan. 2014 26: 108-118.

- This paper offers an application of the mechanismic approach in the context of climate change adaptation as an alternative to the dominant 'barriers to adaptation' approach. The authors find three causal mechanisms: risk-innovation paradox, frame polarization and conflict infection mechanism

[23] Dupuis J, Knoepfel, P: The Adaptation Policy Paradox: the Implementation Deficit of Policies Framed as Climate Change Adaptation. Ecol. and Soc. 201318 (4), 31

[24] Swart R, Biesbroek GR, Lourenço TC: Science of adaptation to climate change and science for adaptation. Frontiers in environmental science 2014 2:29

[25] Beach D: It's all about mechanisms - what process-tracing case studies should be tracing. New Pol. Econ. 2016 21(5)

[26] **Beach D, Pedersen RB: Process-Tracing Methods: Foundations and Guidelines. University of Michigan Press: 2013.

- This book lays the foundation for three types of process tracing methodologies (theory testing, theory building and explaining outcome types of process tracing) and offers various principles, tools and guidelines of how to conduct process tracing in a scientifically rigorous way.

[27] Goertz G, Mahoney J: A tale of two cultures : qualitative and quantitative research in the social sciences. Princeton University Press: 2012.

[28] Bunge M: Mechanism and explanation. Phil. of the Soc. Sci., 1997 27(4): 410-465. 
Pre-print version of the accepted manuscript. Please cite as: Biesbroek, G.R., Dupuis, J. and A. Wellstead (2017) Explaining through Causal Mechanisms: Resilience and Governance of Social-Ecological Systems. Current opinion in Environmental Sustainability 28:64-70.

[29] Pawson R, Tilley N: Realistic evaluation. Sage: 1997.

[30] Hedström P, Ylikoski, P: Causal mechanisms in the social sciences. Ann. Rev. of Sociol. 2010 36: 49-67.

[31] Mahoney J: Beyond correlational analysis: Recent innovations in theory and method. Sociol. Forum, 2001 16(3): 575-593.

[32] Gerring J. The mechanismic worldview: Thinking inside the box. British Jour. of Pol. Sci. 2008 38(1): 161-179.

[33] Elster J: Explaining technical change: A case study in the Philosophy of Science. Cambridge University Press: 1998.

[34] *Falleti TG, Lynch J: From process to mechanism: Varieties of disaggregation . Qual. Sociol., 2008 31(3): 333-339.

- The authors argue that the concept of mechanisms has been used in a variety of ways and for different reasons. The authors argue that causal mechanisms are an ontological position in the social sciences and it is therefore important to disaggregate different types of mechanisms and argue that 'mechanisms-as-cause' is the most important mechanism to identify when explaining cause-effect relationships.

[35] Hecht SS: Cigarette smoking: Cancer risks, carcinogens, and mechanisms. Lang. Archiv. of Surgery, 2006 391(6): 603-613.

[36] Merton, RK: Social theory and social structure. New York Free Press: 1968

[37] Hedström P, Swedberg R: Social mechanisms: An analytical approach to social theory. Cambridge University Press: 1998.

[38] McAdam D, Tarrow S, Tilly C: Methods for measuring mechanisms of contention. Qual. Sociol., 2001 31(3): 307-331.

[39] Merton RK: The Self-Fulfilling Prophecy. The Antioch Rev. 1948 8(2): 193-210.

[40] March JG, Olsen JP: Rediscovering Institutions. Free Press: 1989.

[41] Hood C The Blame Game: Spin, Bureaucracy, and Self-Preservation in Government, Princeton University Press: 2013.

[42] Dewulf A, Bouwen R: Issue Framing in Conversations for Change. The Jour. of Appl. Behav. Sci. 2012 48(2): 168-193.

[43] van Eeten MJG: 'Dialogues of the deaf' on science in policy controversies Sci Pub. Poli. 199926 (3): 185-192.

[44] Thelen K: Historical institutionalism in comparative politics. Ann. Rev. of pol. Sci. 2(1): 369-404. 
Pre-print version of the accepted manuscript. Please cite as: Biesbroek, G.R., Dupuis, J. and A. Wellstead (2017) Explaining through Causal Mechanisms: Resilience and Governance of Social-Ecological Systems. Current opinion in Environmental Sustainability 28:64-70.

[45] Mahoney J, Thelen K: Explaining institutional change: ambiguity, agency, and power Cambridge University Press: 2010

[46] Hacker JS: The divided welfare state: The battle over public and private social benefits in the United States. Cambridge University Press: 2004.

[47] **Falleti TG, Lynch JF: Context and causal mechanisms in political analysis. Comp. Polit. Studies 2009 42(9):1143-1166.

- This paper offers valuable tips and tricks on how to consider contextual condition when researching causal mechanisms. The argument made by the authors is that to explain how and why a hypothesized cause, in a given context, contributes to a particular outcome is needed for meaningful explanations. The authors call for a more substantive role of context in social science research, irrespective of the methodology adopted.

[48] Pawson R: The Science of Evaluation: A Realist Manifesto, Sage Publications Ltd: 2013.

[49] Ludwig J, Kling JR, Mullainathan S: Mechanism Experiments and Policy

Evaluations, J. of Econ. Persp. 2011 25(3) 17-38

[50] Humphreys M, Jacobs AM: Mixing methods: A Bayesian Integration of Qualitative and Quantitative approaches. Am. Pol. Sci. Rev. 109(4): 653-73

[51] Schneider CQ, Rohlfing I: Combining QCA and Process Tracing in Set-Theoretic Multi-Method Research Sociol. Meth. \& Res. 42(4): 559-597

[52] Collier D: Understanding Process Tracing. Pol. Sci. \& Polit. 2011 44(4): 823-830

[53] Kay A, Baker P: What Can Causal Process Tracing Offer to Policy Studies? A

Review of the Literature. Poli. Stud. J. 2015 43: 1-21.

[54] Hinterleitner M: Policy failures, blame games and changes to policy practice. J. of Pub. Pol. Online first: 1-22.

[55] Adams, BE Assessing the Merits of Decentralization: A Framework for Identifying the Causal Mechanisms Influencing Policy Outcomes. Politics and Pol.2016 44(5): 820849. 